\title{
Safety and efficacy of biocompatible perfusion strategy in a contemporary series of patients undergoing coronary artery bypass grafting a two-center study
}

Oz M Shapira", Amit Korach', Frederic Pinaud², Abeer Dabah¹, Yusheng Bao', Jean Jacques Corbeau², Jean-Louis de Brux ${ }^{2}$ and Christophe Baufreton ${ }^{2}$

\begin{abstract}
Objective: The profile of patients referred for coronary artery bypass grafting $(C A B G)$ is continuously changing to include older patients with multiple comorbidities. We assessed the safety and efficacy of a biocompatible perfusion strategy (BPS) in a contemporary series of patients undergoing isolated CABG.

Methods: BPS consisted of a membrane oxygenator, tip-to-tip closed-system heparin-bonded cardiopulmonary bypass circuits without a cardiotomy reservoir, low systemic anticoagulation (target ACT 250-300 sec) using heparin titration curves, low prime volume, avoidance of systemic cooling, and routine use of cell saver and anti-fibrinolytics. Data were prospectively collected using the American Society of Thoracic Surgeons National Adult Cardiac Surgery Database definitions.

Results: 964 consecutive patients (mean age 6611 years, 83\% male) undergoing CABG between 2008 and 2012 were enrolled. 30-day mortality was $1.4 \%$. Rates of postoperative stroke, myocardial infarction, sternal infection and reoperation for bleeding were $0.9 \%, 1.3 \%, 1.9 \%$ and $4.2 \%$, respectively. Average 24 -hour chest tube drainage was $440280 \mathrm{ml}$. Blood products were used in 34\% of patients (total donor exposure of 1.74 .7 units/patient). Predictors of hospital mortality in multivariable analysis were left main disease and preoperative treatment with anti-arrhythmic or immunosuppressive medications. Predictors of allogeneic blood transfusions included older age, small body surface area, female gender, increased serum creatinine, lower preoperative LVEF and hematocrit. Priority of surgery, dual antiplatelet therapy and cardiopulmonary bypass time were not predictors of adverse outcomes or blood transfusions.

Conclusions: In a contemporary cohort of patients undergoing CABG, the use of BPS is safe and effective. It is associated with excellent clinical outcomes and reduced allogeneic blood transfusions.
\end{abstract}

Keywords: Cardiopulmonary Bypass, Coronary Artery Bypass Grafting, Biocompatible, Clinical outcomes, Blood Transfusions

\section{Background}

The use of cardiopulmonary bypass $(\mathrm{CPB})$ in coronary artery bypass grafting (CABG) surgery affords the opportunity to achieve the most important goals of this operation complete revascularization, and performing the anastomoses in an ideal setting of bloodless and

\footnotetext{
* Correspondence: ozshapira@hadassah.org.il

'Department of Cardiothoracic Surgery, Hebrew University, Hadassah Medical Center, POB 12000, Ein-Kerem, Jerusalem 91120, Israel

Full list of author information is available at the end of the article
}

motionless field hence very precisely. These factors translate into clinical benefits of improved patient survival and reduced rates of cardiac events and coronary re-interventions compared to either percutaneous coronary intervention (PCI) or off-pump CABG [1,2].

However, the use of $\mathrm{CPB}$ is associated with side-effects and complications inherent to the pathophysiology of this technology which involve a mechanical pump, bloodforeign surface interaction, blood-air interface and micro-

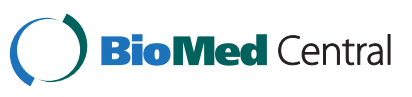

2014 Shapira et al.; licensee BioMed Central. This is an Open Access article distributed under the terms of the Creative Commons Attribution License (http://creativecommons.org/licenses/by/4.0), which permits unrestricted use, distribution, and reproduction in any medium, provided the original work is properly credited. The Creative Commons Public Domain Dedication waiver (http://creativecommons.org/publicdomain/zero/1.0/) applies to the data made available in this article, unless otherwise stated. 
embolization [3]. The end results include systemic inflammatory response, coagulopathy and organ dysfunction [3].

To attenuate these pathophysiological phenomena we and others developed a unique and comprehensive biocompatible perfusion strategy (BPS) in the mid $1990 \mathrm{~s}$ and have shown that indeed this strategy is safe and associated with improved clinical outcomes in patients undergoing CABG, valve and aortic operations [4-8].

Since these reports, however, the profile of patients referred for CABG has fundamentally changed to include older patients with multiple co-morbidities [9]. Patients often are referred in the setting of acute coronary syndrome on dual anti-platelet therapy and after one or more PCIs [10].

Given this substantially higher patient risk profile we aimed to reassess the safety and efficacy of our BPS in a contemporary cohort of patients undergoing CABG. The BPS was independently adopted by the University of Angers in the late 1990 s [11] and was introduced to Hadassah in the beginning of 2008. In this study we evaluate the experience of both institutions over the past five years.

\section{Methods}

Patients

964 consecutive patients undergoing isolated CABG using CPB between January, 2008 and June, 2012 were enrolled. Patients undergoing off-pump CABG or CABG with concomitant procedures were excluded. The study was approved by the Hadassah Hebrew University Medical Center and the University of Angers Helsinki Committees. The need for informed consent was waived by both committees since this was a retrospective study using unidentified data obtained from Departmental databases.

\section{Biocompatible perfusion strategy}

The components of our biocompatible perfusion strategy have been previously described $[4,5]$. Both institutions used an identical uniform protocol. The BPS was adopted by the entire faculty in Angers and two surgeons (out of four) at Hadassah. Briefly, it consisted of tip-to-tip, closedsystem (collapsible closed venous reservoir) heparincoated CPB circuits (Carmeda, Medtronic, Minneapolis, MN, USA, or Bioline, Maquet, Wayne, NJ, USA) with a membrane oxygenator and lack of a cardiotomy reservoir. This circuit configuration nearly eliminates the bloodair interface. Anticoagulation was carefully monitored using heparin titration curves (Hepcon, HMS Plus, Medtronic, Minneapolis, MN, USA) with a target activated clotting time (ACT) of $250300 \mathrm{sec}$. $\mathrm{CPB}$ prime volume was reduced to a minimum using the retrograde autologous priming technique [12]. An important safety practice is strict avoidance of blood stasis within the $\mathrm{CPB}$ circuits, i.e. the volume of blood within a segment of circuit that has no flow must be replaced by a crystalloid solution. Systemic body temperature was kept at near-normothermia (34-36C) avoiding active cooling. We routinely used a cell saver and anti-fibrinolytics (Tranexamic acid). The threshold for red blood cell transfusion was set at hematocrit of less than 20\% during CPB and less than $25 \%$ after CPB. Persistent postoperative bleeding in excess of $300 \mathrm{~mL}$ in the first hour or $500 \mathrm{~mL}$ in the first two hours was considered to be an indication for platelet (5 10 units) and fresh frozen plasma ( 2 units), in the presence of supporting laboratory test results. We did not use thromboelastography. Routine postoperative pharmacological management included oral administration of $100 \mathrm{mg}$ acetylsalicylic acid once daily, started on the first postoperative day, and subcutaneous injection of $1 \mathrm{mg} / \mathrm{Kg}$ of enoxaparin started on the first postoperative day and terminated at discharge. Patients with indwelling drugeluting coronary stents implanted within one year before surgery were treated with oral $75 \mathrm{mg}$ clopidogrel daily in addition to acetylsalicylic acid.

\section{Data collection and study endpoints}

Data in both institutions were prospectively collected and entered into a Departmental database. Data collection was performed using the American Society of Thoracic Surgeons (STS) Adult Cardiac Surgery Database definitions using the STS collection tool version 2.73 [13]. Routine prospective data collection optimized two fundamental requirements data completeness and accuracy. Data collected included baseline patient demographic and risk profile, operative data and 30-day clinical outcomes. The primary study endpoints included 30-day mortality and the incidence and magnitude of allogeneic blood transfusions. Secondary endpoints included rates of major complications including perioperative myocardial infarction, stroke, re-exploration for bleeding and sternal wound infection, time on the respirator and length of hospital and intensive-care unit stay. We focused on these endpoints to assess the safety of the BPS, particularly with regards to the risk of thromboembolic events secondary to low systemic anticoagulation. Bleeding and transfusion requirements were used as endpoints to assess the impact of the BPS on cardiopulmonary-bypass-associated coagulopathy. The STS Database criteria were used to define the primary and secondary endpoints [13].

\section{Statistical analysis}

Continuous variables were expressed as mean standard deviation, median and range. Categorical data were expressed as absolute values with percentages. To examine the primary study- endpoints we performed univariable and multivariable analyses. Continuous variables were analyzed using the Student $t$ test. Categorical data were analyzed using the $\mathrm{X}^{2}$ with Yates correction. Variables with 
a $P$ value of $\leq 0.02$ were entered into stepwise multiple logistic regression models to determine independent predictors of primary study endpoints. Results were expressed as odds ratios (OR) with $95 \%$ confidence intervals (CI). A $\mathrm{P}$ value of 0.05 was considered significant. Statistical analyses were performed using the SPSS for Windows, Version 18.0 software.

\section{Results}

\section{Patients}

There were 964 patients (males $804\{83 \%\}$, females $160\{17 \%\}$ ) with a men age of 6611 years (range 32 to 89 years). The patients baseline profile is depicted in Table 1. It reflects the typical profile of patients referred for CABG nowadays. Notably, 36\% of patients were diabetics, $40 \%$ had left main disease, $57 \%$ had prior MI, $29 \%$ had prior PCI and many had been on aspirin, a second antiplatelet agent or heparin.

\section{Table 1 Baseline patient profile}

\begin{tabular}{ll}
\hline Variable & $\begin{array}{l}\text { Percent or mean, } \\
\text { SD (Median, Range), (n = 964) }\end{array}$ \\
\hline Age (Years) & $6611(66,32$ 89) \\
Gender (M/F) & $804(83 \%) / 160(17 \%)$ \\
Hypertension & $694(72 \%)$ \\
Diabetes mellitus & $345(36 \%)$ \\
Peripheral vascular disease & $184(19 \%)$ \\
Prior cerebrovascular accident & $62(6 \%)$ \\
Renal failure on dialysis & $13(1.3 \%)$ \\
Chronic obstructive pulmonary disease & $90(9 \%)$ \\
Prior myocardial infarction & $556(58 \%)$ \\
Prior Percutaneous Coronary & $282(29 \%)$ \\
Intervention & \\
Preoperative intra-aortic balloon pump & $42(4.3 \%)$ \\
Preoperative medications &
\end{tabular}

\section{Operative and perfusion profile}

Operative data are summarized in Table 2. A large proportion of patients were operated non-electively. The mean number of grafts reflects the fact that most patients were operated for left main or multi-vessel disease and our strong desire to achieve complete revascularization. The left internal mammary artery was used routinely to graft the left anterior descending coronary artery, regardless of age. Multiple arterial grafts were preferred in patients younger than 70 years of age. Inherent to our perfusion strategy, total heparin and protamine doses were very low compared to conventional standards, resulting in a low ACT.

\section{Clinical outcomes}

Clinical outcomes are summarized in Table 3. The observed major study outcomes were compared to the expected outcomes calculated using the STS Database risk assessment algorithms [13]. Thirty-day mortality, stroke, myocardial infarction and reoperation for bleeding were low and within the STS predicted rates. Overall the rate of postoperative renal failure was higher than expected $(7.4 \%$ vs. $3.0 \%$ ), although only $2.9 \%$ required dialysis. The low rates of major complications translated into short time on the respirator, and short ICU and hospital length of stay. In a subset analysis we compared the results of the two institutions. Clinical outcomes were similar between the two institutions (data not shown).

Table 2 Operative and perfusion data

\begin{tabular}{|c|c|}
\hline Variable & $\begin{array}{l}\text { Percent or mean, } \\
\text { SD (Median, range) }(n=964)\end{array}$ \\
\hline \multicolumn{2}{|l|}{ Priority of surgery } \\
\hline Elective & $546(56.6 \%)$ \\
\hline Urgent & $348(36.1 \%)$ \\
\hline Emergent & $63(6.5 \%)$ \\
\hline Emergent-salvage & $7(0.7 \%)$ \\
\hline Redo surgery & $14(1.5 \%)$ \\
\hline Number of vessels bypassed & $2.70 .8(3,1 \quad 5)$ \\
\hline \multicolumn{2}{|l|}{ Usage of arterial grafts } \\
\hline Left internal mammary artery & $938(97 \%)$ \\
\hline Right internal mammary artery & $267(28 \%)$ \\
\hline Radial artery & $125(13 \%)$ \\
\hline Cardiopulmonary bypass time (min) & $9531(93,19$ 309) \\
\hline Aortic cross-clamp time (min) & $6421(63,12$ 169) \\
\hline Lowest systemic temperature (C) & $3512(35,26 \quad 37)$ \\
\hline Total heparin dose (mg/Kg) & $1.91 .0(1.7,0.1-8.6)$ \\
\hline Total protamine dose (mg/Kg) & $1.00 .5(0.9,0 \quad 5.4)$ \\
\hline Highest ACT during CPB (sec) & $360326(335,130$ 999) \\
\hline Lowest ACT during CPB (sec) & $27342(264,139 \quad 524)$ \\
\hline
\end{tabular}


Table 3 Clinical outcomes

\begin{tabular}{|c|c|c|}
\hline Outcome & $\begin{array}{l}\text { Observed } \\
\text { rate }(n=964)\end{array}$ & $\begin{array}{l}\text { STS expected } \\
\text { rate }^{*} n=964 \text { ) }\end{array}$ \\
\hline 30-day mortality & $14(1.4 \%)$ & $2.0 \%$ \\
\hline Reoperation for bleeding & $41(4.2 \%)$ & $6.0 \%$ \\
\hline Postoperative stroke & $9(0.9 \%)$ & $1.0 \%$ \\
\hline Postoperative sternal infection & $18(1.9 \%)$ & $0.5 \%$ \\
\hline Postoperative renal failure & $71(7.4 \%)$ & $3.0 \%$ \\
\hline Postoperative Ml & $13(1.3 \%)$ & \\
\hline Postoperative atrial fibrillation & $241(25 \%)$ & \\
\hline Time on the respirator (hours) & $1429(8,2 \quad 432)$ & \\
\hline ICU length of stay (hours) & $7473(48,0 \quad 1008)$ & \\
\hline Hospital length of stay (days) & $87(10,2 \quad 142)$ & \\
\hline
\end{tabular}

*Predicted outcome rate based on the American Society of Thoracic Surgeons Database risk-assessment algorithms [13].

\section{Bleeding and allogeneic blood transfusions}

The data on bleeding and transfusion are summarized in Table 4 and Figure 1. Median 24-hour chest tube drainage was $380 \mathrm{ml}$. Two thirds of the patients did not receive any allogeneic blood product during their admission. Those receiving blood products were exposed to a small number of donors. Discharge hematocrit was lower than the admission, but greater than $30 \%$ and without apparent adverse clinical effects.

\section{Predictors of study end-points}

Using multivariable logistic regression analyses we assessed the predictors of 30-day mortality and allogeneic blood transfusions. The data are summarized in Table 5. Independent predictors of mortality include left main disease and preoperative treatment with anti-arrhythmic and immunosuppressive medications. Independent predictors of allogeneic transfusions include advanced age, small body surface area and female gender. High preoperative

Table 4 Bleeding and transfusion data

\begin{tabular}{|c|c|}
\hline Variable & $\begin{array}{l}\text { Percent or mean, } \\
\text { SD (Median, range) } n=964 \text { ) }\end{array}$ \\
\hline 24-hour chest tube drainage $(\mathrm{ml})$ & $439280(380,8 \quad 2740)$ \\
\hline Allogeneic blood products transfusion & $325(33.7 \%)$ \\
\hline \multicolumn{2}{|l|}{ Magnitude of Donor Units Transfused } \\
\hline Red Blood Cells (units) & $1.01 .9(0,0 \quad 17)$ \\
\hline Fresh Frozen Plasma (units) & $0.31 .2(0,0 \quad 18)$ \\
\hline Platelets (units)* & $0.31 .8(0,0 \quad 22)$ \\
\hline Cryoprecipitate (units)* & $0.11 .1(0,0 \quad 20)$ \\
\hline Total (units) & $1.74 .7(0,0 \quad 70)$ \\
\hline Preoperative hematocrit (\%) & $40.74 .6(41.1,24.0-56.9)$ \\
\hline Discharge hematocrit (\%) & $33.49 .3(32.9,22.7-28.4)$ \\
\hline
\end{tabular}

*One pack of platelets contains five units (five donors) and one pack of cryoprecipitate contains ten units (ten donors). hematocrit and LVEF were associated with reduced risk of transfusions. Advanced age and priority of surgery were not predictors of mortality. Also, the study site (Hadassah or Angers) and dual anti-platelet therapy were not predictors of mortality, or blood transfusions.

\section{Discussion}

The mid-term results of the Syntax trial published recently re-confirmed that $C A B G$ is associated with improved survival and fewer major adverse cardiac events compared to PCI in patients with multi-vessel and complex left main coronary artery disease [1]. These advantages are particularly apparent in diabetic patients [14]. The superiority of CABG is related to a fundamental attribute of the procedure the ability to achieve a long-lasting complete myocardial revascularization. Precise vascular anastomoses are an important determinant of short and long-term graft patency. Use of CPB provides the optimal conditions necessary to perform the anastomoses including stable hemodynamics and bloodless and motionless surgical field. Although in selected and very experienced center the goals of CABG can be achieved using the beating-heart technique, recent large scale trials studies have shown that the off-pump CABG technique is at best similar or inferior to the on-pump technique $[2,15]$. However, use of $\mathrm{CPB}$ is associated with side effects inherent to the technology [3].

The side effects inherent to $\mathrm{CPB}$ originate mostly from exposure of blood to a large foreign surface, the non-physiological blood-air interphase, mandatory anticoagulation, physical trauma to blood components, microembolization and hypothermia [3]. These primary processes induce activation of multiple cascades such as the intrinsic and extrinsic coagulation system, the complement and kalikrein systems as well as cellular components, leading to intense systemic inflammatory response. Altogether, these pathophysiological processes result in coagulopathy and end-organ dysfunction [3].

The comprehensive biocompatible perfusion strategy adopted by both institutions addresses many of these issues. We use membrane oxygenators and $\mathrm{CPB}$ circuits with modified surface coated with heparin and avoid systemic cooling, exposing the blood to a more physiologic conditions and allowing us to employ much lower level of systemic anticoagulation. Precise monitoring of anticoagulation by heparin titration curves in addition to ACT, reduces over- or under dosing of heparin and protamine. Using a closed CPB system without a cardiotomy sucker and a reservoir minimizes the deleterious effects of bloodair interphase. Reducing CPB prime decreases hemodilution. Altogether this set of modifications comprising the BPS result in a marked attenuation of the inflammatory response and coagulopathy [16-18], translating into improved clinical outcomes and reduced need for allogeneic 


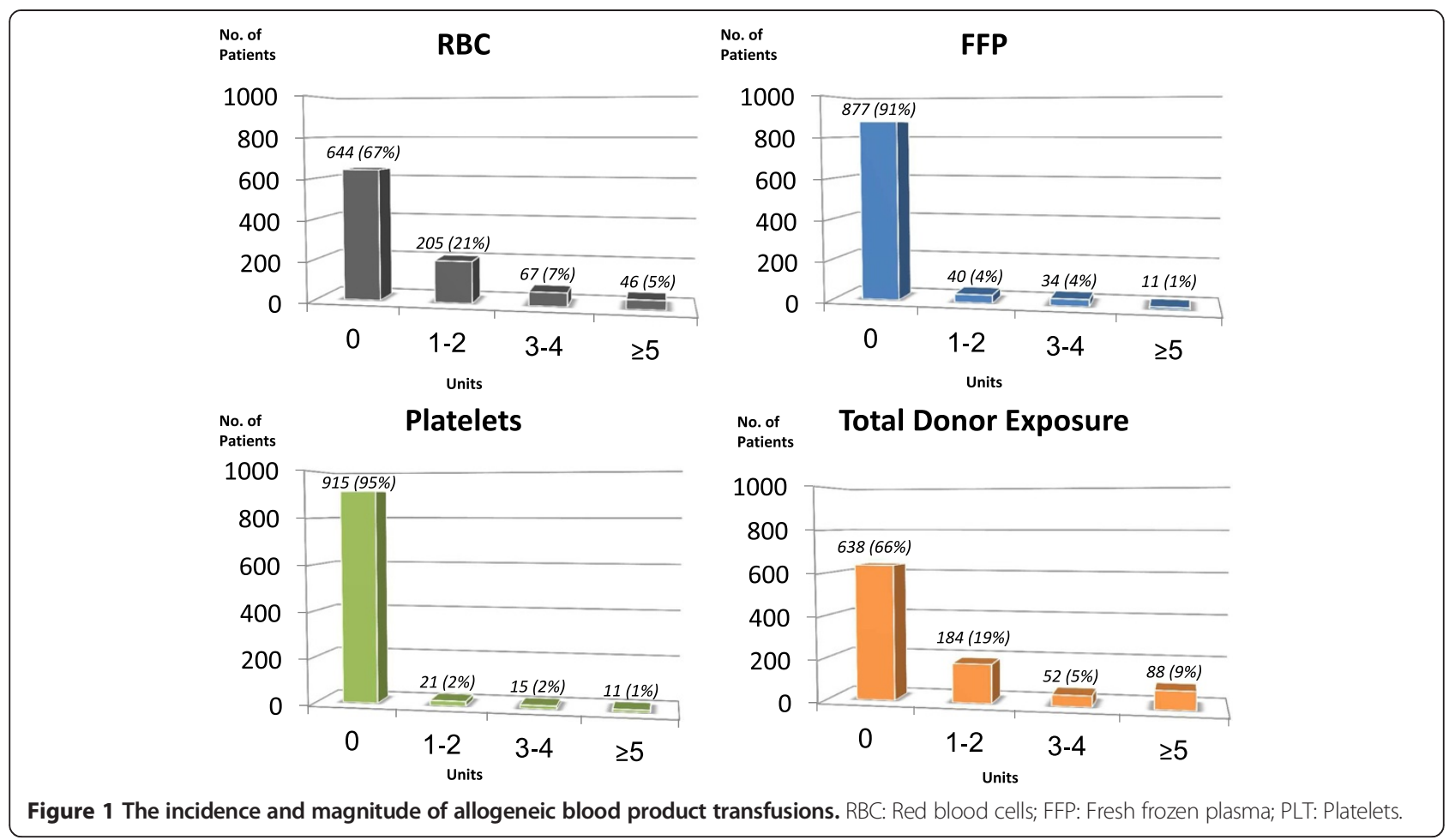

blood transfusions compared to "conventional" perfusion strategy $[4-8,11]$.

The baseline profile of the current patient cohort is typical for patients referred for CABG nowadays [9]. Patients are older with multiple co-morbidities (36\% were diabetics). Most patients had left main and or 3vessel disease. Fifty eight percent had prior MI and 29\% underwent at least one PCI prior to surgery. CABG was performed non-electively in $43 \%$. Despite this high risk

Table 5 Predictors of major study endpoints in multivariable analyses

\begin{tabular}{|c|c|c|c|c|}
\hline Variable & $\begin{array}{l}\text { Odd } \\
\text { ratio }\end{array}$ & \multicolumn{2}{|c|}{$\begin{array}{l}95 \% \text { confidence } \\
\text { intervals }\end{array}$} & $P$ value \\
\hline \multicolumn{5}{|l|}{ A. 30-day mortality } \\
\hline $\begin{array}{l}\text { Preoperative Immunosuppressive } \\
\text { Therapy }\end{array}$ & 12.98 & 2.38 & 70.8 & 0.003 \\
\hline Preoperative anti-arrhythmics & 6.86 & 1.74 & 27.11 & 0.006 \\
\hline Left main disease & 5.77 & 1.48 & 22.5 & 0.012 \\
\hline \multicolumn{5}{|c|}{ B. Allogeneic blood product transfusions } \\
\hline Age & 1.05 & 1.03 & 1.06 & $<0.0001$ \\
\hline Body surface area & 1.004 & 1.00 & 1.007 & 0.025 \\
\hline Female gender & 5.07 & 3.26 & 7.89 & $<0.000$ \\
\hline Preoperative creatinine & 1.65 & 1.15 & 2.36 & 0.007 \\
\hline LVEF & 0.97 & 0.95 & 0.98 & $<0.0001$ \\
\hline Preoperative hematocrit & 0.85 & 0.81 & 0.88 & $<0.0001$ \\
\hline
\end{tabular}

profile, this study demonstrates that the comprehensive BPS remains safe and effective.

The single most important outcome measure to assess quality and safety is procedural mortality. We observed a 30 -day mortality of $1.4 \%$. This is much less than the $2.0 \%$ expected by the STS Database algorithm. The STS Database risk prediction models are derived from data collected on more than two million CABG procedures. Thus, although the current study lacks a control group, the STS risk prediction models for mortality and specific complications serve as very powerful benchmarks against which our results can be compared [19].

Safety is a major concern with any technique and technology that deviates from standard practice. Despite using significantly lower level of systemic anticoagulation, we did not observe clots in the $\mathrm{CPB}$ circuits or experienced oxygenator malfunction. More importantly, the rates of postoperative thromboembolic complications such as CVA, MI and peripheral vascular were low and within expected, based on the STS predictive algorithms.

The BPS was not only safe, but also effective. Despite the high risk profile, clinical outcomes were very acceptable. The observed operative mortality of $1.4 \%$ was lower than the STS predicted mortality of $2.0 \%$. Independent predictors of 30-day mortality were left main and preoperative use of immunosuppressive or anti-arrhythmic medications. Factors such as age, female gender, diabetes, renal failure, non-elective procedure and cardiopulmonary 
bypass time were not associated with increased risk of mortality.

The low rate of CVA $(0.9 \%)$ observed in the current series despite the increased patient risk profile is encouraging. CVA has been considered as the "Achilles heel" of CABG compared with PCI even in recent studies such as Syntax [1]. We attribute the low CVA rate to several factors associated with the BPS. The elimination of the cardiotomy suction from the CPB circuit minimizes bloodair interface, substantially decreasing micro-embolization and systemic inflammatory response well known risk factors for neurological adverse events. Using transcranial Doppler technology, we have previously shown that the number of cerebral micro-emboli was very low and associated with low rates of CVA and neurocognitive dysfunction [5]. In that same study we have also shown that the low anticoagulation protocol reduces thrombin generation during $\mathrm{CPB}$, potentially reducing the risk of thromboembolic complications [5]. In fact, the incidence of other thromboembolic complications we observed such as MI (1.3\%) was lower than expected by the STS prediction for our cohort. We did observe a relatively higher rate of postoperative renal failure. Although it is within the range reported recently after CABG [20], our rate is higher than the STS-predicted. We have no good explanation for this observation and plan to further investigate it.

The BPS was particularly effective in reducing bleeding and transfusion requirements. The observed rate of $4.2 \%$ for reoperation bleeding was lower than that predicted by the STS algorithm (6\%) for our cohort. Median 24hour chest tube drainage was $380 \mathrm{ml}$. Coagulopathy was very infrequently the cause for reoperation. Two thirds of patients did not receive any allogeneic blood products with an average total donor exposure of only 1.7 units. This compares favorably with reported transfusion rates of $39-70 \%$ in recent large-scale reports [21-24]. In contrast to these reports, advanced age, priority of surgery, preoperative dual anti-platelet therapy and $\mathrm{CPB}$ times were not found to be risk factors of increased transfusion. The protective effect of the BPS in patients on dual-antiplatelet therapy has been also reported by Hussaini and colleagues. [25]. It has been previously demonstrated that reoperation for bleeding, the incidence transfusion and the magnitude allogeneic blood transfusion are all independent risk factors of adverse outcomes after cardiac surgery [21-24]. We believe that the favorable clinical outcomes observed in the current study are strongly related to reduced bleeding and very low rate of allogeneic blood product utilization. Finally, reduced rates of major complications, bleeding and transfusion requirements translated into short respiratory support times, short ICU and total hospital lengths of stay.

There are prior studies that found limited value and small clinical benefit to biocompatible CPB circuits [26].
A careful look at these studies reveals that the perfusion technique practiced by different authors was highly variable, missing many essential components of our comprehensive BPS. Examples include using open (versus closed) systems, using $\mathrm{CPB}$ circuits that are not tip-to-tip coated, inclusion of cardiotomy suction and conventional levels of systemic anticoagulation. We strongly believe that in order to be truly biocompatible and clinically effective, our BPS should be implemented as a whole. Eliminating one or more components might have a major adverse impact on its biocompatibility.

This study was not designed to evaluate the costeffectiveness of the BPS. However, it seems that the apparent clinical benefits may very well counter-balance the incremental cost of the technology. LaPar and colleagues recently demonstrated the substantial cost saving achieved by reducing blood transfusions after isolate CABG [24]. This aspect mandates further investigation in our institutions.

Study limitations. Although the data were entered prospectively, this is a retrospective study with the inherent limitation of a selection bias. However, the study cohort is large, consecutive and typical of contemporary practice, allowing meaningful multivariable analyses of outcomes. Although both centers employed a similar perfusion strategy, non-measured differences in practice between institutions might have affected outcomes. Finally, there is no control group. However, the use of the STS risk prediction models provides benchmarks against which the outcomes of this series can be compared. In fact, given our previous prospective randomized trials and the results of the current study, it would be difficult to ethically justify such a trial.

\section{Conclusions}

Despite the study limitations, we conclude that the our data suggest that in a contemporary cohort of patients undergoing CABG, the use of BPS is safe and effective. It is associated with excellent clinical outcomes and reduced allogeneic blood transfusions.

\section{Abbreviations \\ ACT: Activated clotting time; BPS: Biocompatible perfusion strategy; CABG: Coronary artery bypass grafting; CPB: Cardiopulmonary bypass; CVA: Cerebrovascular accident; FFP: Fresh frozen plasma; ICU: Intensive care unit; LVEF: Left ventricular ejection fraction; MI: Myocardial infarction; PCl: Percutaneous coronary intervention; PLT: Platelets; RBC: Red blood cells; STS: Society of Thoracic Surgeons.}

\section{Competing interests}

Prof. Oz M. Shapira and Prof. Christophe Baufreton serve as invited speakers for Medtronic, Western Europe. Other authors have nothing to disclose.

\section{Authors contributions}

OMS: Principal investigator, study design and monitoring, funding, data collection and analysis, writing the manuscript; AK: study design, data review, manuscript review; FP: study design, data review, manuscript review; AD: statistical analysis, manuscript review; YB: establishing the database, data 
collection and analysis, manuscript review; JJC: study design, data review, manuscript review; JLB: study design, data review, manuscript review; CB: Co-PI, Study coordinator in France, study design and monitoring, funding, data collection and analysis, manuscript review. All authors read and approved the final manuscript.

\section{Acknowledgment}

We are greatly indebted to Mrs. Lea Behar, Ms. Emile Dalmayrac and Ms. Marine Reinteau for meticulous data collection.

\section{Funding}

This work was supported in part by Medtronic Western Europe.

\section{Author details}

${ }^{1}$ Department of Cardiothoracic Surgery, Hebrew University, Hadassah Medical Center, POB 12000, Ein-Kerem, Jerusalem 91120, Israel. ${ }^{2}$ Department of Cardiac Surgery, University Hospital of Angers, Angers, France.

Received: 14 July 2014 Accepted: 9 December 2014

Published online: 18 December 2014

\section{References}

1. Mohr FW, Morice MC, Kappetein AP, Feldman TE, Stahle E, Colombo A, Mack MJ, Holmes DR, Morel MA, Van Dyck N, Houle VM, Dawkins KD, Serrruys PW: Coronary artery bypass graft surgery versus percutaneous coronary intervention in patients with three-vessel and left main coronary disease: 5-year follow-up of the randomized clinical Syntax trial. Lancet 2013, 381:629 638.

2. Shroyer AL, Grover FL, Hattler B, Collins JF, McDonald GO, Kozora E, Lucke JC, Baltz JH, Novitzky D: On-pump versus off-pump coronary artery bypass surgery. N Engl J Med 2009, 361:1827 1837

3. Hammon JW, Hines MH: Extracorporeal circulation. In Cohn LH: Cardiac Surgery in the Adult, McGraw Hill Medical, $4^{\text {th }}$ ed, 2012;283 329.

4. Aldea GS, Doursounian M, O Gara P, Treanor PR, Shapira OM, Lazar HL, Shemin RJ: Heparin-bonded circuits with reduced anticoagulation protocol in primary CABG: A prospective randomized trial. Ann Thorac surg 1996, 62:408 410.

5. Aldea GS, O Gara P, Shapira OM, Treanor P, Osman A, Arkin C, Diamond R, Babikian V, Lazar HL, Shemin RJ: Effect of anticoagulation protocol on clinical outcomes in patients undergoing CABG with heparin-bonded cardiopulmonary bypass circuits. Ann Thorac Surg 1998, 65:425 433.

6. Ranucci M, Mazzucco A, Pressotto R, Grillone G, Casati V, Porreca L, Maugeri R, Meli M, Magagna P, Cirri S, Giomarelli P, Lorusso R, de Jong A: Heparin-coated circuits in high risk patients: A multicenter, prospective, randomized trial. Ann Thorac Surg 1999, 67:994 1000.

7. Ovrum E, Tangen G, Tollofsrud S, Skeie B, Ringdal MAL, Istad R, Oystese R: Heparinized cardiopulmonary bypass circuits and low systemic anticoagulation: An analysis of nearly 6000 patients undergoing coronary artery bypass grafting. J Thorac Cardiovasc Surg 2011, 141:1145 1149.

8. Mahmood S, Bilal H, Zaman M, Tang A: Is fully heparin-bonded cardiopulmonary bypass circuit superior to a standard cardiopulmonary bypass circuit? Interact Cardiovasc Thorac Surg 2012, 14:406 414.

9. Aldea GS, Mokadam NA, Melford R Jr, Stewart D, Maynard C, Reisman M, Goss R: Changing volumes, risk profiles, and outcomes of coronary artery bypass grafting and percutaneous coronary interventions. Ann Thorac Surg 2009, 87:1828 1838.

10. Herman CR, Buth KJ, Kent BA, Hirsch GM: Clopidogrel increases blood transfusion and hemorrhagic complications in patients undergoing cardiac surgery. Ann Thorac Surg 2010, 89:397 402.

11. Baufreton C, de Brux JL, Binuani P, Corbeau JJ, Subayi JB, Daniel JC, Treanor P: A Combined approach for improving cardiopulmonary bypass in coronary artery surgery: A pilot study. Perfusion 2002, 17:407 413.

12. Shapira OM, Aldea GS, Treanor P, Chartrand R, DeAndrade K, Lazar HL, Shemin RJ: Reduction of homologous blood transfusion by lowering cardiopulmonary bypass prime volume A prospective randomized study. Ann Thorac Surg 1998, 65:724 730.

13. STS Adult Cardiac Surgery Database Data Collection Form. http://www.sts. org/sites/default/files/documents/STSAdultCVDataCollectionFormV2_81.pdf

14. Farkouh ME, Domanski M, Sleeper LA, Siami FS, Dangas G, Mack M, Yang M, Cohen DJ, Rosenberg Y, Solomon SD, Desai AS, Gersh BJ, Magnuson EA, Lansky A, Boineau R, Weiberger J, Ramanathan K, Sousa JE, Rankin J, Bhargava B, Buse
J, Hueb W, Smith CR, Muratov V, Bansilal S, King S 3d, Bertrand M, Fuster V, Freedom Trial Invesigators: Strategies for multivessel revascularization in patients with diabetes. N Engl J Med 2012, 367:2375 2384.

15. Lamy A, Devereaux PJ, Dorairaj P, Taggart DP, Shengshou H, Paolasso E, Straka Z, Piegas LS, Akar AR, Jain AR, Noiseux N, Padmanabhan C, Bahamondes JC, Novick RJ, Vaijyanath P, Reddy SK, Tao L, Olavegogeascoechea PA, Airan B, Sulling TA, Whitlock RP, Ou Y, Pogue J, Chrolavicius S, Yusuf S, CORONARY Investigators: Effects of off-pump and on-pump coronary artery bypass grafting at 1 year. N Engl J Med 2013, 368:1179 1188 .

16. Lindholm L, Westerberg M, Bengtsson A, Ekroth $R$, Jensen $E$, Jeppsson A: A closed perfusion system with heparin coating and centrifugal pump improves cardiopulmonary bypass biocompatibility in elderly patients. Ann Thorac Surg 2004, 78:2131 2138.

17. Fosse E, Moen O, Johnson E, Semb G, Brockmeier V, Mollnes TE, Fagerhol MK, Venge P: Reduced complement and granulocyte activation with heparin coated cardiopulmonary bypass. Ann Thorac Surg 1994, 58:472 477.

18. Aldea GS, Soltow LO, Chandler WL, Triggs CM, Vocolka CR, Crockott Gl, Shin YT, Curtis WE, Verrier ED: Limitation of thrombin generation, platelet activation and inflammation by elimination of cardiotomy suction in patients undergoing coronary artery bypass grafting treated with heparin bonded circuits. J Thorac Cardiovasc Surg 2002, 123:742 755.

19. Grover FL, Shahian DM, Clark RE, Edwards FH: The STS National Database. Ann Thorac Surg 2014, 97(Suppl 1):S48 S54.

20. Parolari A, Pesce LL, Pacini D, Mazzanti V, Salis S, Sciacovelli C, Rossi F, Alamanni F, Monzino Research Group on Cardiac Surgery Outcomes: Risk factors for perioperative acute kidney injury after cardiac surgery: Role of perioperative management. Ann Thorac Surg 2012, 93:584 591.

21. Koch CG, Li L, Duncan Al, Mihalevic T, Cosgrove DM, Loop FD, Starr NJ, Blackstone EH: Morbidity and mortality associated with red blood cell and blood-component transfusion in isolated coronary artery bypass grafting. Crit Care Med 2006, 34:1608 1616.

22. Vivaaqua A, Koch CG, Yousuf AM, Nowicki I, Blackstone EH, Sabik JF: 3d. Morbidity of bleeding after cardiac surgery is it blood transfusion, reoperation for bleeding, or both? Ann Thorac Surg 2011, 91:1780 1790.

23. Ranucci M, Baryshnikova F, Catelvecchio S, Pelissero G, for the Surgical and Clinical Outcome Research (SCORE) Group: Major bleeding, transfusions and anemia: The deadly triad of cardiac surgery. Ann Thorac Surg 2013, on line ahead of publication.

24. LaPar DJ, Crosby IK, Ailawadi G, Ad N, Choi E, Speiss BD, Rich JB, Kasirajan V, Fonner E Jr, Kron IL, Speir AM, Investigators for the Virginia Cardiac Surgery Quality Initiative: Blood product conservation is associated with improved outcomes and reduced costs after cardiac surgery. J Thorac Cardiovasc Surg 2013, 145:796 803.

25. Hussaini BE, Thatte HS, Rhodes BA, Treanor PR, Birjiniuk V: Thromboresistant surfaces alleviate clopidogrel-related complications in patients undergoing coronary artery bypass grafting. J Thorac Cardiovasc Surg 2011, 141:782 788.

26. Rannuci M, Balduini A, Ditta A, Boncilli A, Brozzi S: A systematic review of biocompatible cardiopulmonary bypass circuits and clinical outcomes. Ann Thorac Surg 2009, 87:1311 1319.

doi:10.1186/s13019-014-0196-3

Cite this article as: Shapira et al:: Safety and efficacy of biocompatible perfusion strategy in a contemporary series of patients undergoing coronary artery bypass grafting a two-center study. Journal of Cardiothoracic Surgery 2014 9:196. 